\title{
Erratum to: Interaction type influences ecological network structure more than local abiotic conditions: evidence from endophytic and endolichenic fungi at a continental scale
}

Pierre-Luc Chagnon ${ }^{1} \cdot$ Jana M. U'Ren $^{2} \cdot$ Jolanta Miadlikowska $^{3} \cdot$ François Lutzoni $^{3}$ • A. Elizabeth Arnold ${ }^{2,4}$

Published online: 22 April 2016

(C) Springer-Verlag Berlin Heidelberg 2016

Erratum to: Oecologia (2016) 180:181-191

DOI 10.1007/s00442-015-3457-5

Owing to an unfortunate oversight, the name of the last author was incorrectly tagged in the xml data. Elizabeth Arnold was tagged as family name, resulting an error in the PubMed.

The online version of the original article can be found under doi:10.1007/s00442-015-3457-5.

Pierre-Luc Chagnon

Pierre-Luc.Chagnon@usherbrooke.ca

1 Université de Sherbrooke, 2500 Boul. de L'Université, Sherbrooke, QC J1K 2R1, Canada

2 School of Plant Sciences, The University of Arizona, Tucson, AZ 85721, USA

3 Department of Biology, Duke University, Durham, NC 27708, USA

4 Department of Ecology and Evolutionary Biology, The University of Arizona, Tucson, AZ 85721, USA 